\title{
Heat Transfer From Elliptic Cylinder Immersed In A Fluidized Bed
}

\author{
M. A. Abd-Rabbo ${ }^{a}$, R. Y. Sakr ${ }^{\mathrm{b}}$, M. A. Mohammad ${ }^{\mathrm{a}}$ and M. M. Mandour ${ }^{\mathrm{c}}$. \\ ${ }^{a}$ Mechanical Engineering Department, Faculty of Engineering, Al-Azhar University. \\ ${ }^{\mathrm{b}}$ Mechanical Engineering Department, Faculty of Engineering Shoubra, Benha University. \\ ${ }^{\mathrm{c}}$ Research Student.
}

\begin{abstract}
In the present work, heat transfer characteristics and flow field from a heated elliptic cylinder immersed in fluidized bed is studied numerically using CFD package. The flow pattern and heat transfer fields around the heated cylinder is predicted using a two fluid Eulerian-Eulerian model coupled with kinetic theory of granular flow (KTGF) with heat transfer. Runs were carried out under uniform heat flux condition, with air as a fluidizing gas and pulverized coal as a bed material. The Reynolds number based on the equivalent cylinder hydraulic diameter, $D_{h}$, was ranged from 941to 1263. The simulation results of the present study showed that, for the range of gas velocity considered, at minimum fluidization velocity, $\operatorname{Re}=$ 914, the $\mathrm{Nu}_{\theta}$ is maximum at the sides of the cylinder and minimum at the stagnation, $\theta=0^{\circ}$, and top, $\theta=180^{\circ}$, of the cylinder. The average Nusselt number for the elliptic cylinder increases with the increase of the fluidization velocity. The present data is compared with a previous well-known correlation from the literature for a circular cylinder and a reasonable deviation is found.
\end{abstract}

Keywords: Heat transfer, CFD, Elliptic cylinder, Local and average Nusselt numbers, Fluidized bed.

\section{Introduction}

Fluidization is the phenomenon of imparting the properties of a fluid to a bed of particulate solids by passing a fluid (liquid or gas) through the material. Fluidized beds are reactors in which fluidization of particulate solids takes place. Fluidized 
beds are commonly used in chemical, biochemical and petrochemical industries in processes such as hydrocarbon cracking, drying of solids, combustion and gasification of coal and biomass, thermal treatment of metals, recovery of energy from gases and hot solid particles, synthesis reactions and coating of particles. Gassolid fluidized systems are characterized by temperature uniformity and high heat transfer coefficients, due to the intense mixture of the solid material by the presence of gas bubbles. Heat transfer and fluid flow around immersed surfaces in packed and fluidized beds have been the focus of a variety of numerical, experimental studies and modelling efforts. The influences of different parameters affect these regimes (eg., thermal conductivity, static height of bed, bed particles (diameter/ type), Superficial fluidization velocity, bubbling, ........ etc ) have been studied and presented extensively by the majority of researchers in the fluidization literature. Kuipers et al. [1] developed a gas-fluidized bed model based on "two-fluid model", TFM, in which both phases were considered to be continuous and fully interpenetrating. The porosity, the pressure, the fluid phase temperature, the solid phase temperature and the velocity fields of both phases in twodimensional Cartesian or axi-symmetrical cylindrical coordinates were measured by computer. Gustavsson and Almstedt, [2] developed a curvilinear two-fluid model solver for simulation of the fluid dynamics of bubbling in fluidized beds with two internal horizontal heat exchanger tubes. The used numerical code, Gemini, was based on the implicit multi-field method (IMF) of Harlow and Amsden for Eulerian two-fluid modelling, assuming no turbulence in the gas or solid phase. Yusuf et al, [3] studied the effect of gas velocity and particle size on heat transfer coefficient from a heated wall in a gas-fluidized bed using the Eulerian-Eulerian approach. A two dimensional simulation of a bubbling bed at ambient conditions with a heated wall at $333 \mathrm{~K}$ is carried out on the in-house code FLOTRACS-MP-3D. Wankhede and Adgulkar, [4] studied the CFD simulations of heat transfer from the immersed small tube in a two-dimensional fluidized bed of different material with different particle diameter. The bubbling fluidized bed simulations were performed using FLUENT 6.0, a commercial finite volume code. Zhao et al, [5] conducted simulations using the combined Computational Fluid Dynamics-Discrete Element Method (CFD-DEM) to analyse particle-particle and particle-fluid heat transfer behaviours by quantifying the contribution to heat transfer coefficient via convection, conduction, and radiation. Armstrong et al, [6] modelled one, two and three heated tubes immersed in fluidized bed reactors using an Eulerian-Eulerian kinetic theory of granular flow model. Teaters, [7] used a (CFD) with and without turbulence modelling to predict the gas-solid hydrodynamics of fluidized beds. He studied a single solids phase glass bead and walnut shell fluidized beds to show the distinction between bubbling, slugging, and turbulent flow regimes by examining void fraction contours and bubble dynamics, as well as by comparison of simulated data with an established trend of standard deviation of pressure versus inlet gas velocity. Perrone and Amelio [8] studied the hydrodynamics and heat transfer between fluidized bed and a heated wall using the Eulerian-Eulerian approach. They used the CFD technique to simulate the bubbling fluidized bed reactor and 
heat transfer between the fluidized bed and a heated surface, to understand the behaviour of gas-solid flow and the bubbles production. Schmidt and Renz [9] conducted numerical simulations to analyse heat transfer between a fluidized bed of Geldart B particles and an immersed tube and showed that the correlation between heat transfer coefficient and the bed hydrodynamics was in theoretical agreement with the packet theory. Gan et al [10] applied CFD-DEM to study heat transfer behaviour in fluidized beds containing non-spherical particles and found that spherical particles had the lowest effective thermal conductivity while ellipsoidal particles gave rise to lower convective heat transfer but higher conductive heat transfer rates. Wahyudi et al [11] conducted 3-D simulations of a fluidized bed with an immersed tube to study hydrodynamics and heat transfer behaviour using CFDDEM and were able to reproduce general hydrodynamic and heat transfer trends, such as pressure drop and the correlation between heat transfer coefficient with varying superficial gas velocity. Li et al, [12] used a (CFD-DEM) model to simulate heat transfer in a pseudo-2D fluidized bed with heat production in the particle phase. All key aspects of the adsorption process (kinetics, equilibrium, and heat effect) were studied separately using Thermo-gravimetric Analysis (TGA) and Simultaneous Thermal Analysis (STA), and subsequently fluidized bed experiments were conducted, by feeding gas mixtures of $\mathrm{CO}_{2}$ and $\mathrm{N}_{2}$ with different $\mathrm{CO}_{2}$ concentrations to the bed, where the total heat of liberation could be controlled. Most studies to date have focused on heat transfer between bed material and surfaces immersed in it. These immersed surfaces are often cylinders with circular cross section although there are a lot of researchers proved that [17-20], the cylinders with non-circular cross section especially elliptic ones have good aerodynamic characteristics better than that in circular ones. So, the present study focused on the combination between fluidized bed hydrodynamic behaviour and flow patterns of particles around the tube in its vicinity and their influence on the tube-to-bed heat transfer rate. This may be assessed as a computational data with high spatial resolution to understand the very complex behaviour of fluidized bed operations.

\section{CFD simulation}

Due to the high particle concentrations in gas-solid fluidized beds the particle interactions cannot be neglected. In fact, the solid phase has similar properties as a continuous fluid. Therefore, the Eulerian approach is an efficient method for the numerical simulation of fluidized beds. This model allows for the presence of two different phases in one control volume of the grid by introducing the volume fraction variable. By using the kinetic theory of granular flows, the viscous forces and the solid pressure of the particle phase can be described as a function of the socalled granular temperature.

\section{Governing equations}


The following governing and constitutive equations were solved using computational fluid dynamics ANSYS Fluent 14.5 to predict the bed hydrodynamics of pulverized coal. Gas phase, air, was considered to be the primary phase, while solid phase, pulverized coal, was considered to be secondary or dispersed phase.

- Governing equations for flow and heat transfer in a fluidized bed reator:

- Volume fraction equation

$\varepsilon_{g}+\varepsilon_{s}=1$

\section{- Conservation of mass}

Gas: $\frac{\partial\left(\varepsilon_{g} \rho_{g}\right)}{\partial t}+\nabla \cdot\left(\varepsilon_{g} \rho_{g} \vec{v}_{g}\right)=0$

Solid: $\frac{\partial\left(\varepsilon_{s} \rho_{s}\right)}{\partial t}+\nabla \cdot\left(\varepsilon_{s} \rho_{s} \vec{v}_{s}\right)=0$

where $\varepsilon, \rho$ and $v$ are the volume fraction, density and local velocity, respectively

\section{- Conservation of momentum}

Gas: $\frac{\partial\left(\varepsilon_{g} \rho_{g} \vec{v}_{g}\right)}{\partial t}+\nabla \cdot\left(\varepsilon_{g} \rho_{g} \vec{v}_{g} \vec{v}_{g}\right)=-\varepsilon_{g} \nabla P+\nabla \cdot \overline{\overline{\tau_{g}}}+\varepsilon_{g} \rho_{g} \overrightarrow{\mathrm{g}}+K_{g s}\left(\vec{v}_{g}-\vec{v}_{s}\right)$

Solid: $\frac{\partial\left(\varepsilon_{s} \rho_{s} \vec{v}_{s}\right)}{\partial t}+\nabla \cdot\left(\varepsilon_{s} \rho_{s} \vec{v}_{s} \vec{v}_{s}\right)=-\varepsilon_{s} \nabla P-\nabla P_{s}+\nabla \cdot \overline{\bar{\tau}}_{s}+\varepsilon_{s} \rho_{s} \overrightarrow{\mathrm{g}}+K_{g s}\left(\vec{v}_{g}-\vec{v}_{s}\right)$

Where $\mathrm{K}_{\mathrm{gs}}$ is the gas-solid momentum exchange coefficient, $\mathrm{P}$ is gas phase static pressure, $\mathrm{P}_{\mathrm{s}}$ is solid pressure, $\mathrm{g}$ is the gravity acceleration and $\overline{\overline{\tau_{s}}}$ and $\overline{\overline{\tau_{g}}}$ are and stress tensors, respectively.

\section{The stress tensors}

Gas: $\overline{\overline{\tau_{g}}}=\varepsilon_{g} \mu_{g} \nabla \cdot \vec{v}_{g}+2 \varepsilon_{g} \mu_{g} \nabla \cdot \vec{v}_{g}^{T}-\frac{2}{3} \varepsilon_{g} \mu_{g} \nabla \cdot \vec{v}_{g} I$

Solid: $\overline{\overline{\tau_{s}}}=\varepsilon_{s} \mu_{b} \nabla \cdot \vec{v}_{s} \bar{I}+\varepsilon_{s} \mu_{s} \nabla \cdot \vec{v}_{s}+2 \varepsilon_{s} \mu_{s} \nabla \cdot \vec{v}_{s}^{T}-\frac{2}{3} \varepsilon_{s} \mu_{s} \nabla \cdot \vec{v}_{s} \bar{I}$

Where $\mu_{b}, \mu_{g}$ and $\mu_{s}$ are granular bulk, gas and solid viscosities, respectively.

\section{- Conservation of energy}

Gas: $\frac{\partial\left(\varepsilon_{g} \rho_{g} H_{g}\right)}{\partial t}+\nabla \cdot\left(\varepsilon_{g} \rho_{g} \vec{v}_{g} H_{g}\right)=\nabla \cdot \varepsilon_{g} K_{g}^{e f f} \nabla T_{g}-h_{g s}\left(T_{s}-T_{g}\right)$

Solid: $\frac{\partial\left(\varepsilon_{s} \rho_{s} H_{s}\right)}{\partial t}+\nabla \cdot\left(\varepsilon_{s} \rho_{s} \vec{v}_{s} H_{s}\right)=\nabla \cdot \varepsilon_{s} K_{s}^{e f f} \nabla T_{s}-h_{s g}\left(T_{s}-T_{g}\right)$

Where $H_{g}$ and $H_{s}$ are specific enthalpy, $K_{g}^{\text {eff }}$ and $K_{s}^{\text {eff }}$ are effective thermal conductivity for gas and solid phases and $h_{g s}$ is the heat exchange between the gas and solid phases, respectively.

\section{- Constitutive equations used to close the governing equations:}

Syamlal O'Brien drag model

$$
\begin{aligned}
& K_{g s}=\frac{3}{4} \frac{\varepsilon_{s} \varepsilon_{g} \rho_{g}}{v_{t, s}^{2} d_{s}} C_{D}\left(\frac{R e_{s}}{v_{r, s}}\right)\left|\vec{v}_{s}-\vec{v}_{g}\right| \\
& C_{D}=\left(0.63+\frac{4.8}{\sqrt{R e_{s} v_{r, s}}}\right)^{2} \\
& v_{r, s}=0.5\left(A-0.06 R e_{s}+\sqrt{\left(0.06 R e_{s}\right)^{2}+0.12 R e_{s}(2 B-A)+A^{2}}\right) \\
& A=\varepsilon_{g}^{4.14}, B=\varepsilon_{g}^{2.65} \quad \text { for } \varepsilon_{g}>0.85
\end{aligned}
$$


$A=\varepsilon_{g}^{4.14}, B=0.8 \varepsilon_{g}^{1.28}$ for $\varepsilon_{g} \leq 0.85$

\section{Kinetic fluctuation energy}

$\frac{3}{2}\left[\frac{\partial}{\partial_{t}}\left(\rho_{s} \varepsilon_{s} \theta_{s}\right)+\nabla \cdot\left(\rho_{s} \varepsilon_{s} \vec{v}_{s} \theta_{s}\right)\right]=\left(-\rho_{s} \bar{I}+\overline{\overline{\tau_{s}}}\right): \nabla \cdot \overrightarrow{v_{s}}+\nabla \cdot\left(K_{\theta_{s}} \nabla \theta_{s}\right)-\gamma_{\theta_{s}}+\emptyset_{g s}$

$\gamma_{\theta_{s}}=\frac{12(1-e)^{2} \mathrm{~g}_{0}}{d_{s} \sqrt{\pi}} \varepsilon_{s}^{2} \rho_{s} \theta_{s}^{3 / 2} \quad \emptyset_{g s}=-3 K_{g s} \theta_{s}$

$K_{\theta_{s}}=\frac{15 d_{s} \rho_{s} \varepsilon_{s} \sqrt{\theta_{s} \pi}}{4(41-33 \eta)}\left[1+\frac{12}{5} \eta^{2}(4 \eta-3) \varepsilon_{s} \mathrm{~g}_{0}+\frac{16}{15 \pi}(41-33 \eta) \eta \varepsilon_{s} \mathrm{~g}_{0}\right]$

$\eta=\frac{1}{2}(1+e)$

Where $\left(-\rho_{s} \bar{I}+\overline{\overline{\tau_{s}}}\right): \nabla \cdot \overrightarrow{v_{s}}$ is the generation of energy by the solid tensor, $K_{\theta_{s}} \nabla \theta_{s}$ is the diffusion of energy while the term of $K_{\theta_{s}}$ is the diffusion coefficient, $\gamma_{\theta_{s}}$ is the collisional dissipation of energy, $g_{0}$ is the radial distribution function, and $\emptyset_{g s}$ is the energy change between the gas or solid and solid phases.

\section{Solid shear viscosity}

$\mu_{s}=\mu_{s, c o l}+\mu_{s, s k i n}+\mu_{s, f r}$

\section{Collisional viscosity}

$\mu_{s, \text { col }}=\frac{4}{5} \varepsilon_{s} d_{s} \rho_{s} \mathrm{~g}_{0}(1+e)\left(\frac{\theta_{s}}{\pi}\right)^{1 / 2}$

Kinetic viscosity

$\mu_{s, \text { skin }}=\frac{10 d_{s} \rho_{s} \sqrt{\theta_{s} \pi}}{96 \varepsilon_{s} g_{0}(1+e)}\left[1+\frac{2}{5} \varepsilon_{s} g_{0}(1+e)(3 e-1)\right]$

\section{Frictional viscosity}

$\mu_{s, f r}=\frac{\rho_{s} \sin \emptyset}{2 \sqrt{I_{2 D}}}$

\section{Solid bulk viscosity}

$\lambda_{s}=\frac{4}{3} \varepsilon_{s} d_{s} \rho_{s} \mathrm{~g}_{0}(1+e)\left(\frac{\theta_{s}}{\pi}\right)^{1 / 2}$

\section{Particle pressure}

$P_{s}=\varepsilon_{s} \rho_{s} \theta_{s}+2 \rho_{s}(1+e) \varepsilon_{s}^{2} \mathrm{~g}_{0} \theta_{s}$

Radial distribution function

$\mathrm{g}_{0}=\left[1-\left(\frac{\varepsilon_{s}}{\varepsilon_{s, \max }}\right)^{1 / 3}\right]^{-1}$

Where $\theta_{s}$ is the granular temperature, $\mathrm{g}_{0}$ is the radial distribution function and $\mathrm{e}$ is the restitution coefficient. The radial distribution function $\mathrm{g}_{0}$ is related to probability of collisions between grains when the solid granular phase becomes dense. The restitution coefficient $\mathrm{e}$ is proportional to the energy loss in particle-particle collision. Its value is unity and zero for elastic and in-plastic collisions, respectively. The value of 0.9 was chosen in this study. 


\section{Solid phase boundary conditions}

Velocity

$\vec{u}_{s, w}=-\frac{6 \mu_{s} \varepsilon_{s, \max }}{\sqrt{3} \sqrt{0} \pi \varphi \rho_{s} \varepsilon_{s} \mathrm{~g}_{0}} \frac{\partial \vec{v}_{s, w}}{\partial n}$

Granular temperature

$\theta_{s}=-\frac{K_{\theta_{S}}}{\gamma_{w}} \frac{\partial \theta}{\partial n}+\frac{\sqrt{3} \pi \varphi \rho_{s} \varepsilon_{S} \mathrm{~g}_{0} \vec{v}_{s, \text { slip }}^{2} \theta^{3 / 2}}{6 \gamma_{w} \varepsilon_{s, \max }} \gamma_{w}=\frac{\sqrt{3} \pi\left(1-e_{w}^{2}\right) \rho_{s} \varepsilon_{s} \mathrm{~g}_{0} \theta^{3 / 2}}{4 \varepsilon_{s, \max }}$

\section{Model set-up}

Two dimensional rectangular bed reactor $(\mathrm{D}=0.2 \mathrm{~m}, \mathrm{H}=1.5 \mathrm{~m})$ is used for the numerical simulation model, as shown in Fig (1), to reduce the solution time. The static head of the bed, $\mathrm{h}_{0}$, is $0.25 \mathrm{~m}$ and air is introduced as a fluidizing gas through the domain inlet while the outlet is considered as pressure outlet and the other boundaries are considered as walls. The gas phase is considered to be no-slip condition while the solid phase is allowed to slip partially on walls. The gas and solid phases are set initially to the atmospheric temperature of $25^{\circ} \mathrm{C}$. Wall heat flux for heating cylinder is assumed to be constant at $13.3 \mathrm{KW} / \mathrm{m}^{2}$. The simulations were performed for 24000 time steps with a time step size of $0.00025 \mathrm{~s}$ to ensure quick convergence with a maximum of 20 iterations per time step and the simulation was run for $6 \mathrm{~s}$ of real time. For more details see Tables (1) and (2) which summarize numerical parameters used in the simulation. Multiphase Eulerian Eulerian approach, treating the coal particles as granules has been used to simulate the flow. Conservation equations for each phase are derived to obtain a set of equations, which have similar structure for all phases. In granular flows, these equations are closed by application of kinetic theory and the Syamlal O'Brien drag model [13] is used to model the interaction between these phases. The transient computational model was created in CFD software, FLUENT 14.5. The phase coupled SIMPLE algorithm along with second order upwind scheme has been used to solve the transport equations using the finite volume approach.

\subsection{Grid sensitivity analysis}

To obtain optimum grid size that gives good accuracy and reasonable computational time, grid sizes of $1 \mathrm{~mm}, 2 \mathrm{~mm}$, and $5 \mathrm{~mm}$ are examined in the present work. Structured meshing method is used for meshing the geometry. In the present study, quadrilateral cells are used to mesh the general area of the column with a uniform cell size of $2 \mathrm{~mm}$. The cell size in the region near the heated wall varied from 0.02 $\mathrm{mm}$ to $2 \mathrm{~mm}$ within increasing factor of 1.22 from the heated wall to obtain the local temperature gradients. 


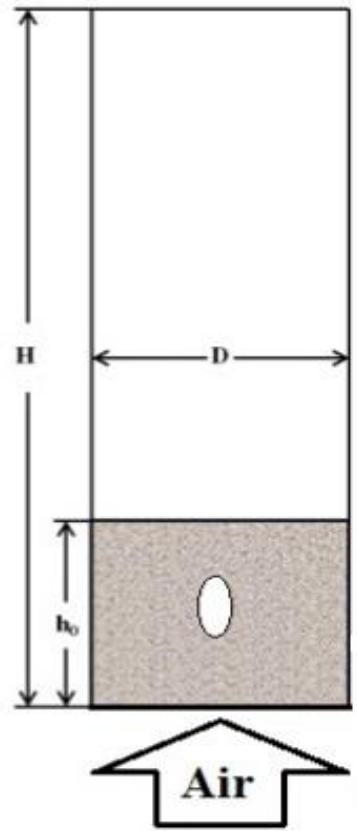

Figure (1): Schematic diagram of the numerical setup.

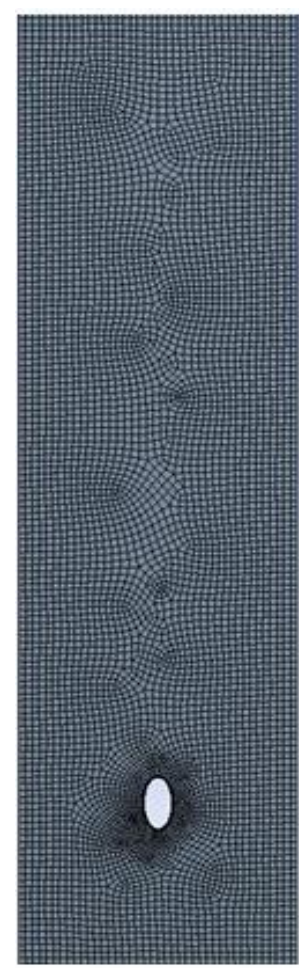

Figure (2): Snapshot of mesh display 
Table (1): Properties of phases used in the present simulation

\begin{tabular}{|ll|}
\hline Air properties (Gas phase): & \\
- Density, $\boldsymbol{\rho}_{\mathbf{g}}$ & $1.1545 \mathrm{~kg} / \mathrm{m}^{3}$ \\
- Viscosity, $\boldsymbol{\mu}_{\mathbf{g}}$ & $1.884 * 10^{-5} \mathrm{~kg} / \mathrm{m} . \mathrm{s}$ \\
- Specific heat, $\mathbf{C}_{\mathbf{P g}}$ & $1007 \mathrm{~J} / \mathrm{kg}^{\mathrm{o}} \mathrm{c}$ \\
- Thermal conductivity, $\mathbf{k}_{\mathbf{g}}$ & $0.026606 \mathrm{~W} / \mathrm{m}^{\circ} \mathrm{c}$ \\
- Prandtl number, $\mathbf{P}_{\mathbf{r}}=\boldsymbol{\mu}_{\mathbf{g}} \mathbf{C}_{\mathbf{P g}} / \mathbf{k}_{\mathbf{g}}$ & 0.7275 \\
Coal properties $($ Solid phase): & \\
- Particle mean diameter, $\mathbf{d}_{\mathbf{p}}$ & 0.002 \\
- Density, $\boldsymbol{\rho}_{\mathbf{s}}$ & $354 \mathrm{~kg} / \mathrm{m}^{3}$ \\
- Thermal conductivity, $\mathbf{k}_{\mathbf{s}}$ & $0.49 \mathrm{~W} / \mathrm{m}^{\circ} \mathrm{c}$ \\
- Specific heat, $\mathbf{C}_{\mathbf{P s}}$ & $910 \mathrm{~J} / \mathrm{kg}^{\circ} \mathrm{c}$ \\
- Volume fraction & 0.6 \\
\hline
\end{tabular}

Table (2): Parameters and boundary conditions used in the present simulation

\begin{tabular}{|c|c|}
\hline Flow type & Laminar \\
\hline Gas-solid model & Eulerian-Eulerian with KTGF \\
\hline Wall boundary & $\begin{array}{l}\text { No-slip condition for gas, slip } \\
\text { condition for solid }\end{array}$ \\
\hline Time step & $0.00025 \mathrm{~s}$ \\
\hline Convergence criteria & 0.001 \\
\hline Under relaxation factors & $\begin{array}{l}0.5 \text { for pressure, } 0.2 \text { for momentum and } \\
0.6 \text { for volume fraction. }\end{array}$ \\
\hline Maximum solid packing volume fraction & 0.63 \\
\hline Pressure velocity coupling & SIMPLE \\
\hline Discretization scheme & Second order upwind \\
\hline Outlet condition & Atmospheric pressure \\
\hline Superficial gas velocity & $0.34,0.37,0.39,0.42,0.44 \mathrm{~m} / \mathrm{s}$ \\
\hline Minimum fluidizing velocity & $0.31 \mathrm{~m} / \mathrm{s}$ \\
\hline Particle-particle restitution coefficient & 0.9 \\
\hline Particle-wall restitution coefficient & 0.9 \\
\hline
\end{tabular}

\section{Results and discussion}

Heat transfer from elliptic cylinder immersed in fluidized bed in addition to flow pattern are investigated numerically within the Reynolds number range of $914 \leq \mathrm{Re}$ $\leq 1263$. The dimensionless coefficients, $\mathrm{Nu}$ and $\mathrm{Re}$ numbers have been calculated based on cylinder hydraulic diameter, $\mathrm{D}_{\mathrm{h}}=4 \mathrm{~A}_{\mathrm{c}} / \mathrm{P}$. The simulation runs are carried out at constant heat flux condition. 


\subsection{Heat transfer}

\subsection{1- Local Nusselt number}

The local heat transfer coefficients are taken close to the tube within the reactor of the single tube simulation at $6 \mathrm{~s}$ around the tube surface. Figure (3) shows the predicted local Nusselt number distribution around the tube circumference. For the range of gas velocity considered, at minimum fluidization velocity, $\operatorname{Re}=914$, the $\mathrm{Nu}_{\theta}$ is maximum at the sides of the cylinder and minimum at the stagnation, $\theta=0^{\circ}$, and top, $\theta=180^{\circ}$, of the cylinder. Minima are found on the top of the tube, where a "stagnant cap" of solids tend to have a long residence time, and around the bottom, where a permanent film of gas is observed to shroud the downward facing surface of the tube [14]. At higher gas velocities, $R e \geq 1262$, the maximum coefficient is predicted to move around to the top, about the $\pm 135^{\circ}$ position, of the tube due to the regular dislodgement of particles there and more frequent contact of the upper tube surface with particles, as compared to the sides and bottom [15]. All curves for in between Reynolds numbers provide similar trends but different magnitudes. Generally, this figure shows that the local Nusselt number is increased with the increasing the Reynolds number.

\subsubsection{Average Nusselt Number}

Effect of gas velocity on the average Nusselt Number, based on particles diameter, $\mathrm{Nu}_{\mathrm{p}}$, at different $\left(\mathrm{U}_{\mathrm{sup}} / \mathrm{U}_{\mathrm{mf}}\right)$ for single tube is shown in Figure (4). The predicted average Nusselt Number increases, $\mathrm{Nu}_{\mathrm{p}}$, as $\left(\mathrm{U}_{\text {sup }} / \mathrm{U}_{\mathrm{mf}}\right)$ increase. Since there is no available data about elliptic cylinder immersed in fluidized bed, the present data is compared with the correlation proposed by Gelperin et al [16] for a circular cylinder as:

$N u_{p}=0.815 \operatorname{Pr}^{0.33} \frac{6(1-\varepsilon)}{\varepsilon}\left[\frac{R e_{p}}{6(1-\varepsilon)}\right]^{0.32}$

Figure (4) shows that, a reasonable deviation about $11-30 \%$ is found between present data and the results obtained from Gelperin et al [16]. This deviation may be attributed to the change in operating conditions. In addition to, the Nusselt numbers in case of elliptic tube have higher rates than that of circular tube. This may be attributed to the lesser region of motionless material for the elliptic than for the circular tube as shown in Fig (5). Therefore, the part of the surface washed by the stream is greater for the elliptical tube than for the circular one, and so heat transfer is more effective and uniform [14].

\subsection{Volume fraction of solid}

The gas fluidized bed reactor is modelled with single horizontal heated immersed tube. The contour plots of the particle volume fraction within the reactor is displayed through the 6.0 seconds in Figure (6). These contours of volume fractions of pulverized coal and air in the reactors obtained at air velocity of $0.42 \mathrm{~m} / \mathrm{s}$ for initial static bed height $0.25 \mathrm{~m}$ after the quasi steady state is achieved. The colour scale given to the right gives the value of volume fraction corresponding to the colour. Also, it is observed that particle volume fraction changed with time till there 
is no significant change in bed profile which indicates that the fluidized bed reached in a quasi-steady state. Once the fully developed quasi-steady state is reached, then calculate the averaged quantities in terms of time, axial and radial direction. It can be observed that, in the early stages of the single immersed tube model a collection of air below the tube forms. A larger air bubble from the inlet ascends through the bed with time whilst the small air voidage under the tube continues up blanketing round the tube. At $0.5 \mathrm{~S}$, this small voidage separates from the tube to continue up through the bed whilst the larger bubble from the inlet reaches the tube and begins to encase the tube. As expected, the presence of large bubbles within the bed causes a higher bed height expansion which is seen at $0.25-1$ s. Once the bed dynamics have been established these small bubbles continue with similar sizes resulting in little variation in bed height.

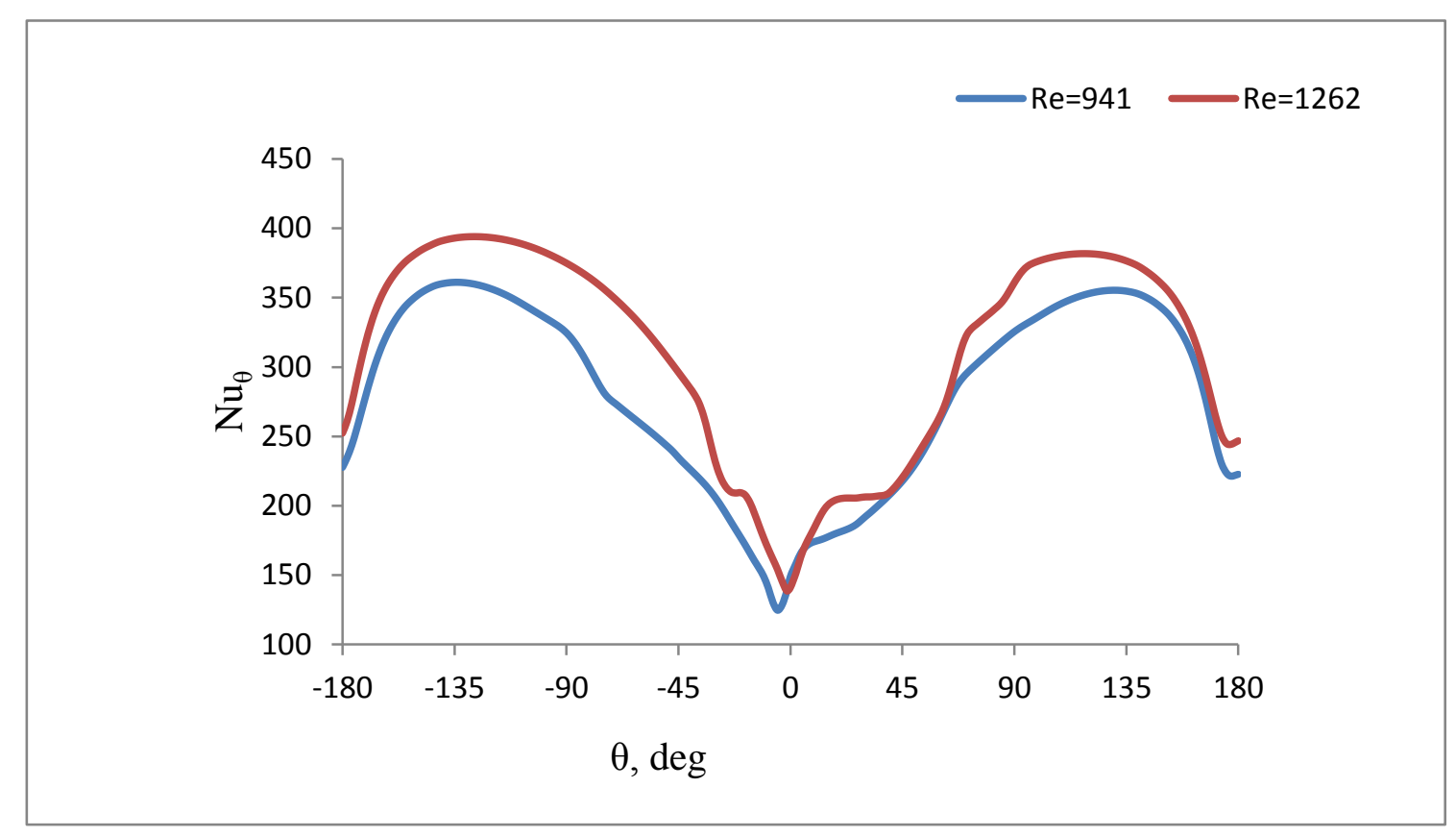

Figure (3): Local predicted Nusselt number at $6 \mathrm{~s}$ versus Circumferential location $\theta$, deg for the full circumference of the immersed tube comparing to the Re. 


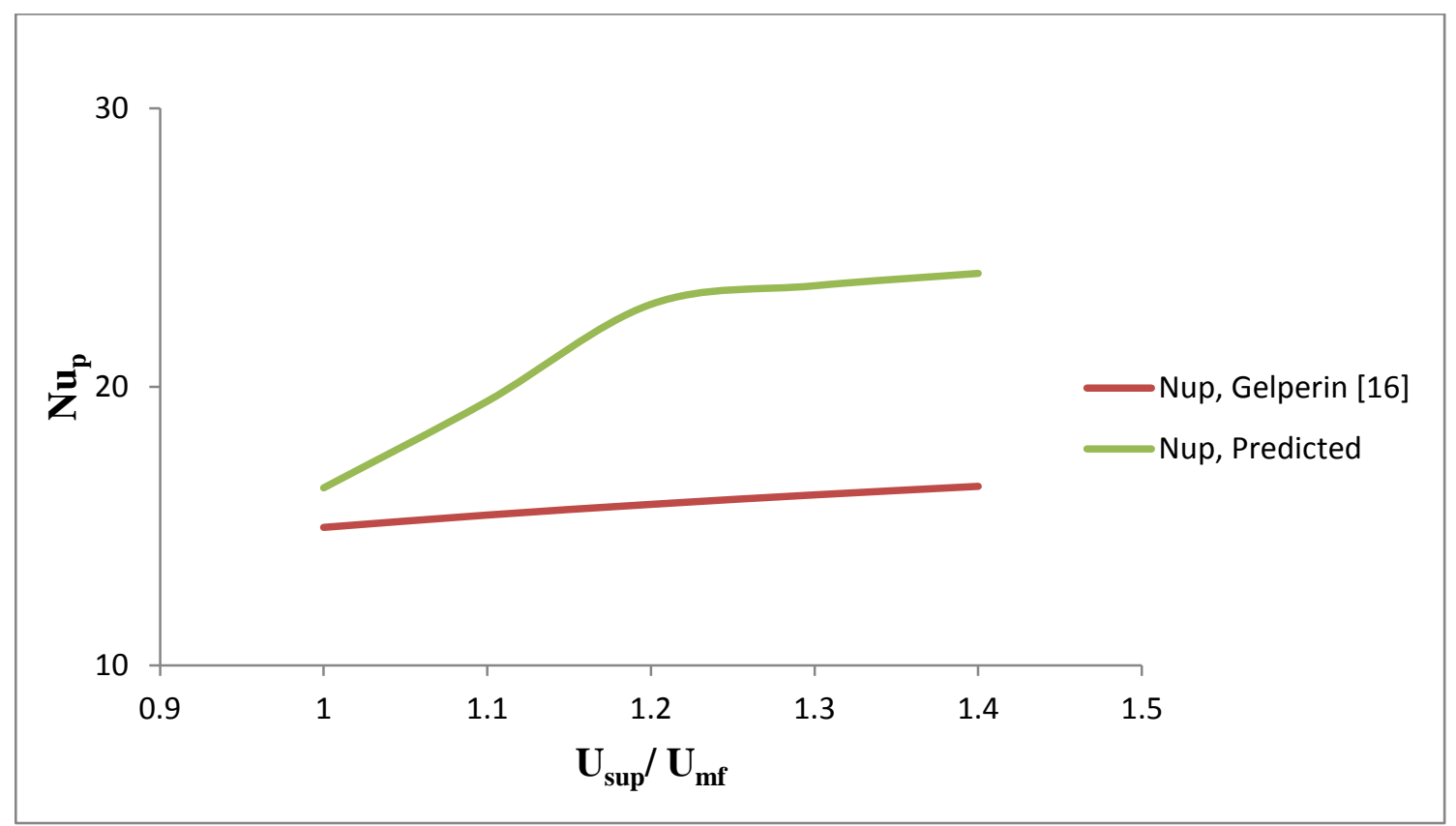

Figure (4): Predicted average Nusselt number, $\mathrm{Nu}_{\mathrm{p}}$, versus fluidization number, $\mathrm{U}_{\text {sup }} / \mathrm{U}_{\mathrm{mf}}$.

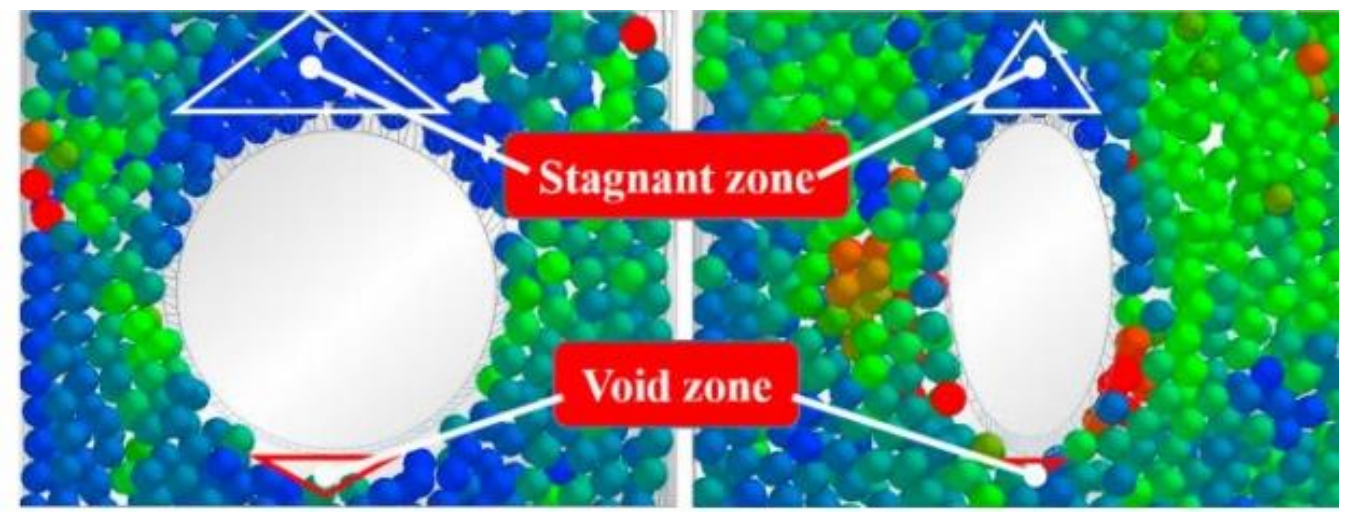

Figure (5): Flow pattern of circular and elliptical tubes [14]. 


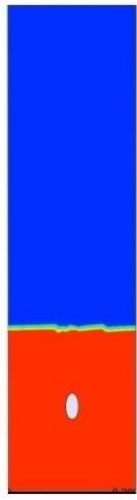

$0.00 \mathrm{~S}$

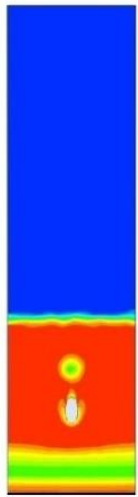

$0.25 \mathrm{~S}$

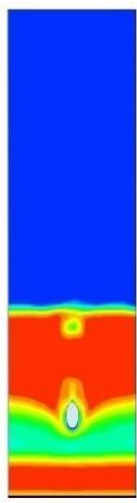

$0.50 \mathrm{~S}$

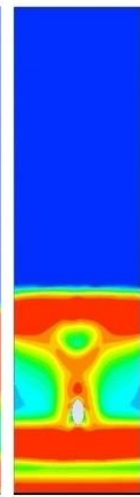

$0.75 \mathrm{~S}$

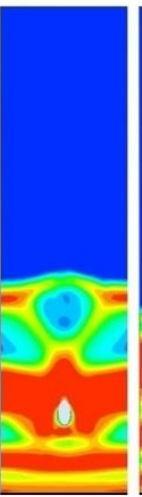

$1.00 \mathrm{~S}$

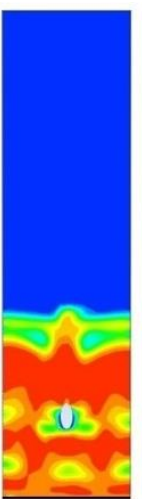

$2.00 \mathrm{~S}$

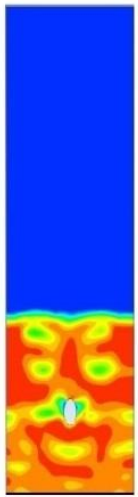

$3.00 \mathrm{~S}$

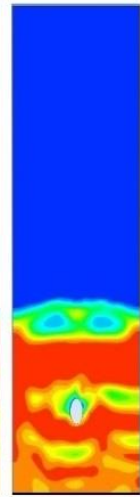

$4.00 \mathrm{~S}$

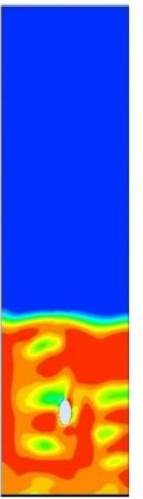

$5.00 \mathrm{~S}$
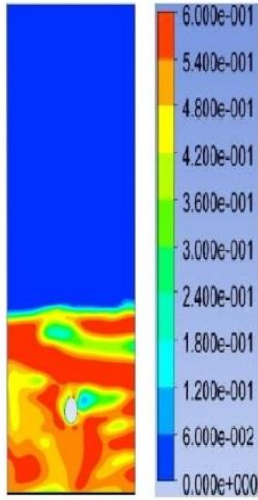

$6.00 \mathrm{~S}$

Figure (6): Contours of solid volume fraction of $2 \mathrm{~mm}$ mean diameter at air velocity of $0.44 \mathrm{~m} / \mathrm{s}$ with respect of time for initial bed height $0.25 \mathrm{~m}$.

\subsection{Velocity vectors}

The velocity vectors are helpful in determining flow patterns in fluidized bed. Figures (7) shows the velocity vectors of air and pulverized coal in the fluidized bed reactor obtained at minimum fluidization velocity for initial static bed height $0.25 \mathrm{~m}$ and particles of diameter size $2 \mathrm{~mm}$ after the quasi steady state has been achieved. From the vector of solids it can be seen that, there is a small length vigorous movement of the solid particles at the bottom part of the bed. In the upper part of the fluidizing section, there is a circulatory motion of the particles with movement near the wall in the downward direction while that in the central zone is upward. But in case of the velocity vector of air in the column shows always an upward trend. However, the velocity is more in fluidized section of the bed compared to the part of the column which contains no solids. This is because less space is available for air to flow between bed particles and tubes.
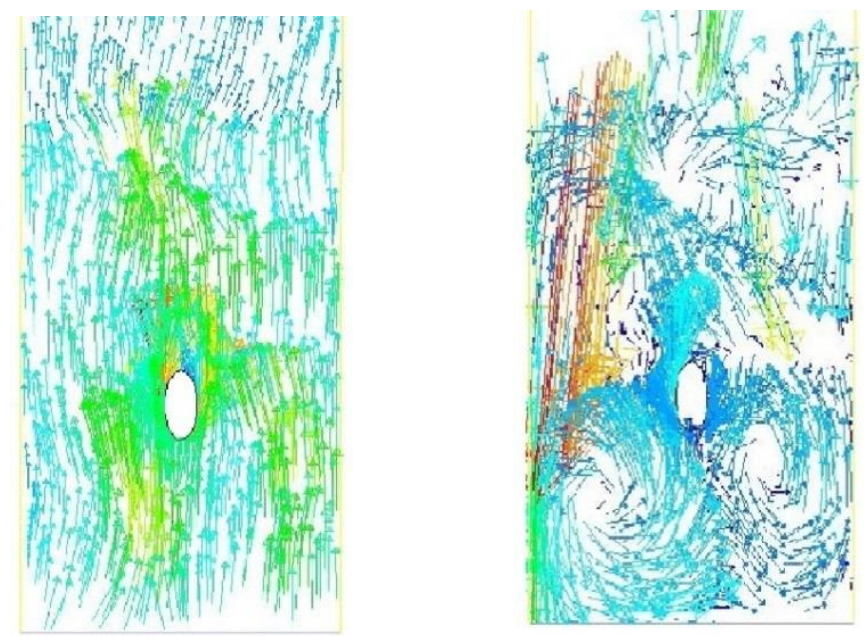

Figure (7): Velocity vector of air and solid respectively, in FBR of single tube. 


\subsection{Pressure Drop}

The pressure drop across the bed is an indication about mixing of the bed material with the fluidizing fluid that controls formation of channel and slug. The fluidization number versus the predicted bed pressure drop variation across the fluidized bed having single elliptic tube submerged in a bed of pulverized coal of mean particle diameters $d p=2 \mathrm{~mm}$ is shown in Figure (8). It is observed that, with the increase in fluidization velocity, a uniform pressure drop is obtained because the bed voidage is more i.e. the gap between the particles is more. The particles are in suspended condition and air flows freely between the particles [21].

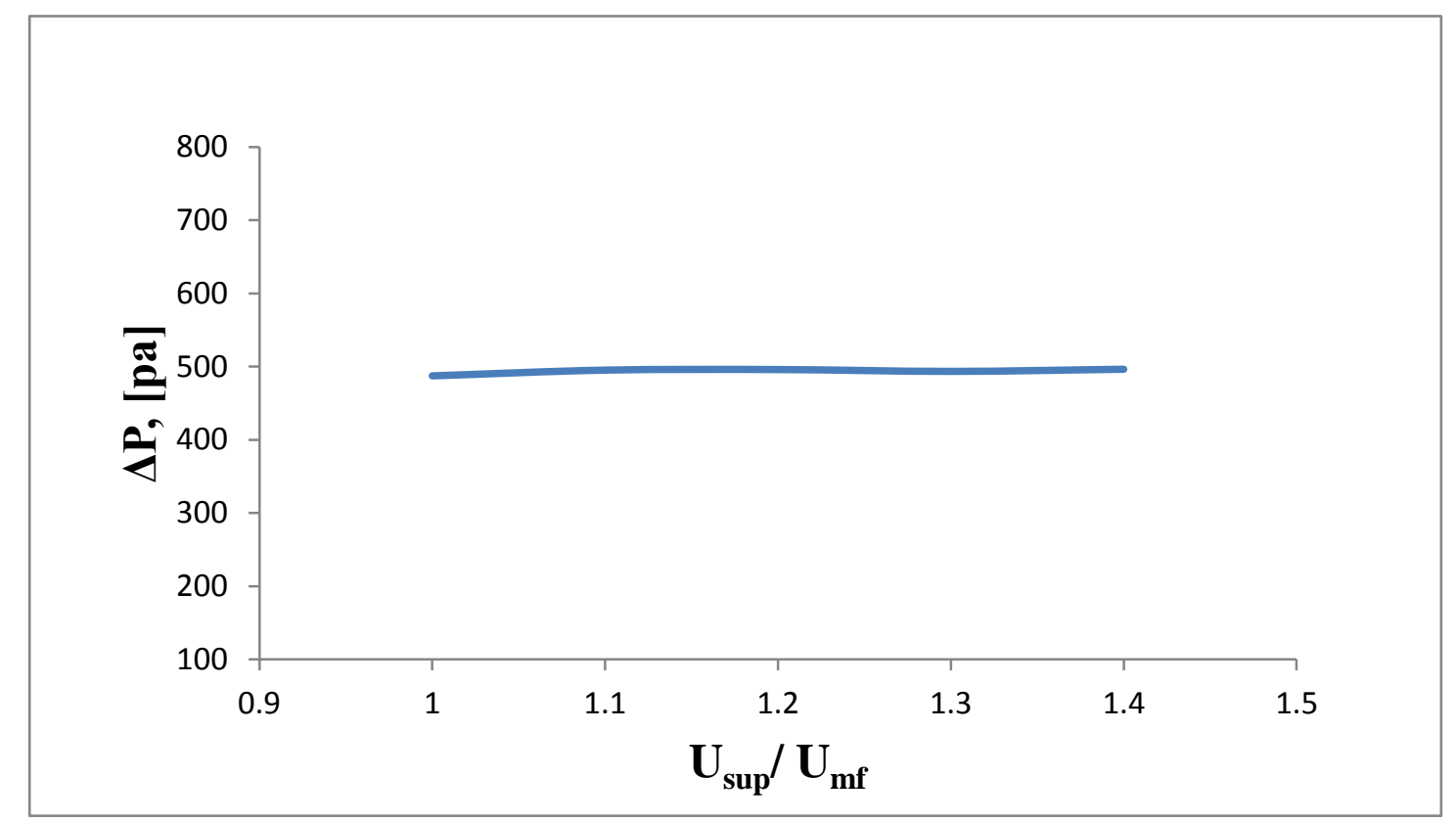

Figure (8): Predicted pressure drop across the fluidized bed of $\mathrm{dp}=2 \mathrm{~mm}$.

\section{Conclusions}

The heat transfer characteristics and flow patterns around elliptic cylinder immersed in fluidized bed of pulverized coal were studied numerically with air as a fluidizing gas. A numerical set-up was designed using CFD, 2-D, ANSYS 14.5, TFM, Eulerian-Eulerian with KTGF to predict the heat transfer and bed hydrodynamics of pulverized coal. The simulation results of the present study showed that, for the range of gas velocity considered, at minimum fluidization velocity, $\operatorname{Re}=914$, the $\mathrm{Nu}_{\theta}$ is maximum at the sides of the cylinder and minimum at the stagnation, $\theta=0^{\circ}$, and top, $\theta=180^{\circ}$, of the cylinder. The average Nusselt number for the elliptic cylinder increases with the increase of the Reynolds number. Insignificant increase in the pressure drop across the fluidized bed with increase in fluidization number. 


\section{Nomenclature}

$\mathrm{A}_{c}$ Cross-sectional area of heated cylinder, $\mathrm{m}^{2}$.

$A_{s}$ Surface area of heated cylinder, $m^{2}$.

$\mathrm{C}_{\mathrm{P}}$ Specific heat, $\mathrm{J} / \mathrm{kg}{ }^{\circ} \mathrm{C}$.

D Reactor width, $\mathrm{m}$.

$\mathrm{D}_{\mathrm{h}}$ Hydraulic diameter of elliptic cylinder, $\mathrm{m}$.

$\mathrm{H}$ Reactor height, $\mathrm{m}$.

$\mathrm{h}$ heat exchange between the gas and solid phases.

$\mathrm{h}_{0} \quad$ Static bed height of solid, $\mathrm{m}$.

$\mathrm{k}$ Thermal conductivity, $\mathrm{W} / \mathrm{m}{ }^{\circ} \mathrm{c}$.

$\mathrm{K}^{\text {eff }}$ Effective thermal conductivity, W/m ${ }^{\circ} \mathrm{c}$.

$\mathrm{K}_{\mathrm{gs}}$ Gas-solid momentum exchange coefficient.

$\mathrm{K}_{\theta_{\mathrm{s}}}$ The diffusion coefficient for granular energy, $\mathrm{Kg} / \mathrm{sm}$.

$\mathrm{Nu}_{\mathrm{p}}$ Average Nusselt number, based on particles diameter.

$\mathrm{Nu}_{\theta}$ Local Nusselt number.

P pressure, $\mathrm{kg} / \mathrm{m}^{2}$.

$\mathrm{P}$ The perimeter of the tested cylinder, $\mathrm{m}$.

Pr Prandtl number.

Re Reynolds number.

$\mathrm{Re}_{\mathrm{p}}$ Reynolds number, based on particles diameter.

$\mathrm{t}$ Time, s.

$\mathrm{U}_{\text {sup }}$ Superficial air velocity, $\mathrm{m} / \mathrm{s}$.

$\mathrm{U}_{\mathrm{mf}}$ Minimum fluidization velocity, $\mathrm{m} / \mathrm{s}$.

v Local velocity, $\mathrm{m} / \mathrm{s}$

\section{Greek letters}

$\boldsymbol{\varepsilon}$ Bed void fraction.

$\Delta \mathrm{P}$ Static pressure drop across the bed, $\mathrm{Pa}$.

$\rho$ Density, $\mathrm{kg} / \mathrm{m}^{3}$

$\overline{\overline{\tau_{s}}}$ Stress tensor, $\mathrm{Pa}$.

$\mu$ Viscosity, $\mathrm{kg} / \mathrm{m}$.s

$\emptyset_{\text {gs }}$ Energy change between the gas or solid phases, $\mathrm{Kg} / \mathrm{s}^{3} \mathrm{~m}$.

$\gamma_{\theta_{s}}$ The collisional dissipation of energy, $\mathrm{Kg} / \mathrm{s}^{3} \mathrm{~m}$.

$\theta_{\mathrm{s}}$ Granular temperature, $\mathrm{m}^{2} / \mathrm{s}^{2}$.

FBR Fluidized bed reactor.

CFD Computational fluid dynamics.

TFM Two fluid model.

KTGF Kinetic theory for granular flow.

\section{Subscripts}

$\theta$ local angle in the axial direction.

a air. 
c cylinder's cross-section.

g gas.

gs gas-solid

mf minimum fluidization.

p particle

S solid.

sup superficial.

\section{References}

[1] J. A. M. Kuipers, K. J. Van Duin, F. P. H. Van Beckum and W. P. M. Van Swaaij, "A numerical model of gas-fluidized bed", Chemical engineering science, Vol. 47, No. 8, pp. 1913-1924, 1992.

[2] M. Gustavsson and A. E. Almstedt, "Numerical simulation of fluid dynamics in fluidized beds with horizontal heat exchanger tubes", Chemical engineering science, Vol. 55, pp. 857-866, 2000.

[3] R. Yusuf, M. C. Melaaen and V. Mathiesen, "CFD modeling of heat transfer in gas fluidized bed", Fourth international conference on CFD in the oil and gas, Metallurgical \& Process Industries, SINTEF/ NTNU, Trondheim, Norway, June 6$8,2005$.

[4] U. S. Wankhede and D. D. Adgulkar, "CFD simulations of heat transfer in a bubbling fluidized bed for different materials", First international conference on emerging trends in engineering and technology, pp. 1094-1098, 2008.

[5]Y. Zhao Z, A.B. Yu and P. Zulli, "A new computational method for studying heat transfer in fluid bed reactors", Powder technology, Vol. 197, PP. 102-110, 2010 .

[6] L.M. Armstrong and S. Gu, K.H. Luo, "The influence of multiple tubes on the tube-to-bed heat transfer in a fluidized bed", International journal of multiphase flow, Vol. 36, PP. 916-929, 2010.

[7] L. Teaters, "A computational study of the hydrodynamics of gas-solid fluidized beds ", M. sc. Thesis, Mechanical engineering, Virginia polytechnic institute and state university, (Virginia Tech), May 31, 2012.

[8] D. Perrone and M. Amelio, "A preliminary study of hydrodynamics and heat transfer in a bubbling fluidized bed containing sand particle using CFD", 69th conference of the Italian thermal machines engineering association, ATI2014, Energy procedia, Vol. 81, PP. 1041-1054, 2015.

[9] A. Schmidt, U. Renz, "Eulerian computation of heat transfer in fluidized beds" Chemical engineering science, Vol. 54, PP. 5515-5522, 1999.

[10] J. Gan, Z. Zhou and A. Yu, "Particle scale study of heat transfer in packed and fluidized beds of ellipsoidal particles", Chemical engineering science, Vol. 144, PP. 201-215, 2016. 
[11] H. Wahyudi, K. Chu and A. Yu, "3D particle-scale modeling of gas-solids flow and heat transfer in fluidized beds with an immersed tube", International journal of heat and mass transfer, Vol. 97, PP. 521-537, 2016.

[12] Z. Li, T.C.E. Janssen, K.A. Buist, N.G. Deen, M. van Sint Annaland and J.A.M. Kuipers, "Experimental and simulation study of heat transfer in fluidized beds with heat production", Chemical engineering journal, Vol. 317, PP. 242-257, 2017.

[13] M. Syamlal, T. J. O'Brien, "Computer simulation of bubbles in a fluidized bed", AIChE Symposium Series, Vol. 85, PP: 22-31, 1989.

[14] Z. Tan, Z. Guo, J. Yang and Q. Wang, "Numerical investigation of heat transfer for elliptical tube in granular flow using DEM", Energy Procedia, Vol. 158,PP: 5504-5509, 2019.

[15] R. Chandran, J. C. Chen, F. W. Staub, "Local heat transfer coefficients around horizontal tubes in fluidized beds", AIChE J, Vol. 102, no. 2, PP:152-157, 1980.

[16]N. I. Gelperin, V. Y. Kruglikov, and V. G. Ainshtein, "Heat transfer between a fluidized bed and the surface of a single tube in longitudinal and transverse gas flow" (in Russian), Khim. Prom, 6, 358, 1958.

[17] J. M. Park, O. J. Kim, S. J. Kim and Y-C. Shin, "Heat transfer characteristics of circular and elliptic cylinders in cross flow", Advances in Mechanical Engineering, Vol. 7, No. 11, pp. 1-8, 2015.

[18] N. El Gharbi, A. Kheiri, M. El Ganaoui and R. Blanchard "Numerical optimization of heat exchangers with circular and non-circular shapes", Case Studies in Thermal Engineering, Vol. 6, PP: 194-203, 2015.

[19] N. S. Berbish, "Heat transfer and flow behavior around four staggered elliptic cylinders in cross flow", Heat Mass Transfer, Vol. 47, PP: 287-300, 2011.

[20] C. Veerraju and M. R. Gopal, "Heat and mass transfer studies on elliptical metal hydride tubes and tube banks", International Journal of Hydrogen Energy, Vol. 34, PP: 4340-4350, 2009.

[21] M. A. Moawed, N. S. Berbish, A. A. Allam, A. R. El-Shamy and K. M. ElShazly, "Heat transfer between fluidized bed and horizontal bundle of tubes in a vertical channel", International journal of chemical reactor engineering, Vol. 8, PP: 1-27, 2010. 